\title{
Blindness and retinal disorder associated with clomifene citrate: Cases series assessment
}

\author{
Mulugeta Russom ${ }^{1 *}$, Bastola Pradeep ${ }^{2}$, Mehari Zeregabr ${ }^{1}$, Kahsay Fessehatzion ${ }^{3}$ and Natnael Araya ${ }^{4}$ \\ ${ }^{1}$ Eritrean Pharmacovigilance Centre, Asmara, Eritrea \\ ${ }^{2}$ Retina Specialist, Consultant Ophthalmologist, Berhan Eye National Referral Hospital, Asmara, Eritrea \\ ${ }^{3}$ Ophthalmologist, Berhan Eye National Referral Hospital, Asmara, Eritrea \\ ${ }^{4}$ Mendefera Zonal Referral Hospital, Mendefera, Eritrea
}

\begin{abstract}
Background: Clomifene Citrate has been associated with various visual disturbances. However, we found no published study that associate Clomifene citrate and blindness. The Eritrean Pharmacovigilance Centre received one case of retinal detachment while on use of Clomifene citrate that caused irreversible blindness. Hence, the purpose of this study is to assess the causal relationship between Clomifene citrate and blindness in general and retinal detachment in particular.

Methods: Search on the WHO global individual case safety reports (ICSRs) database, VigiBase ${ }^{\mathrm{TM}}$, was made on August 1, 2016 with "Clomifene Citrate" as drug substance and "blindness", "retinal disorder" and "retinal detachment" as reaction-terms for the search criteria. Results generated were exported to excel spreadsheet for quantitative and qualitative analysis. All the cases then subjected to Austin Bradford-Hill Criteria to assess the causal association.

Results: A total of 24 cases of blindness and retinal disorder associated with Clomifene Citrate were retrieved from the WHO global database, VigiBase ${ }^{\mathrm{TM}}$. In all the cases, Clomifene Citrate was reported as the sole suspected drug and in all but three cases no concomitant drugs were reported. There were two cases of blindness in which reaction abated with sequelae following withdrawal of Clomifene Citrate. Ten of the cases were marked as serious and seriousness was not highlighted on the rest of cases; even though the reported reaction terms are potentially serious by definition. The combination of Clomifene Citrate with retinal disorder, blindness and retinal detachment gave all positive IC value.
\end{abstract}

Conclusions: This finding supports a causal relationship between Clomifene citrate and blindness. Hence, further study is required to evaluate the safety of Clomifene citrate that would help for sound decision making.

\section{Introduction}

Clomifene (clomiphene) citrate is an orally administered nonsteroidal agent, which has both estrogenic and anti-estrogenic properties used for induction of ovulation since 1962. It is the treatment of choice in women with ovulatory disorders who are normally oestrogenized [1]. Clomifene Citrate has been associated with visual problems, especially with increased dosage or duration of therapy [2]. Visual problems like blurred vision, photophobia, diplopia, scotomata, phosphenes, periphlebitis, central retinal vein occlusion, optic neuropathy and palinopsias has been associated with clomiphene citrate [3-7].

During post-marketing surveillance in patients on clomifene citrate; abnormal accommodation, cataract, eye pain, macular edema, optic neuritis, photopsia, posterior vitreous detachment, retinal hemorrhage, retinal thrombosis, retinal vascular spasm, temporary or prolonged loss of vision, possibly irreversible have been reported $[2,8]$.

Recently, the Eritrean Pharmacovigilance Centre received one case of retinal detachment while on use of Clomifene citrate that caused irreversible blindness. Hence, the purpose of this study is to assess the causal relationship between Clomifene citrate and blindness in general and retinal detachment in particular.

\section{Methods}

Search on the WHO global individual case safety reports (ICSRs) database, VigiBase ${ }^{\mathrm{TM}}$, was made on August 1, 2016 with 'Clomifene Citrate' as drug substance and 'blindness', 'retinal disorder' and 'retinal detachment' as reaction-terms for the search criteria. Results generated were exported to excel spreadsheet for analysis. All relevant data mining like the IC value, completeness score, rechallenge and dechallenge information of the individual case safety reports (ICSRs) were performed using VigiLyze $^{\mathrm{TM}}$, a tool developed by the Uppsala Monitoring Center for data mining and analysis of ICSRs in VigiBase. Information Component (IC) value is the disproportionality measure of ICSRs in VigiBase. Positive IC value suggests a potential signal. Onset dates, patient age/sex, and dates of administration of a medicine were checked to avoid any duplication of data. All the cases then subjected to Austin Bradford-Hill Criteria to assess the causal association.

Naranjo probability scale was used to assess the causality of the case reported from Eritrea. To assess expectedness or labeling of the adverse drug reactions (ADRs), updated Summary of Product Characteristics (SPC) of Clomifene Citrate manufacturers, published articles or case

Correspondence to: Mulugeta Russom, Head, Eritrean Pharmacovigilance Center, National Medicines and Food Administration, Asmara, Eritrea, Tel: +291-7197450, E-mail: satiswt@gmail.com

Key words: Clomifene citrate, blindness, retinal disorder

Received: May 19, 2017; Accepted: June 15, 2017; Published: June 19, 2017 
reports, updated and reliable medical reference books and the US FDA official drug information website were used [9].

\section{Results}

A total of 24 cases of blindness, retinal disorder and retinal detachment associated with Clomifene Citrate (reported between 1982 and August 1,2016) were retrieved from the WHO global database, VigiBase $^{\mathrm{TM}}$. Some of the retinal problems reported following the use of clomifene citrate are retinal damage (2), retinal disorder (6), retinal vascular disorder(1), retinopathy(2) and retinal detachment(2). The cases were submitted from USA(16), United Kingdom(4), Canada(1), Eritrea(1), New Zealand(1) and Turkey(1). Of all the cases, three cases of blindness were implicated in new born children and possibly associated as mothers had taken Clomifene Citrate before or during pregnancy. Hence, the number of cases reduced to 21 (Table 1).

The combination of Clomifene Citrate with retinal disorder and blindness gave positive IC value (Table 1). In all the cases retrieved from VigiBase, Clomifene Citrate was reported as the sole suspected drug and in all but three cases, no concomitant drugs were reported.

Outcome of the reactions is either unknown or not documented in most of the cases. Of the 21 cases, two recovered with sequelae, two reported as not yet recovered and one case worsen (Table 2). Time to onset was reported in eight of the cases; of which reaction started on the second day following the initiation treatment with Clomifene citrate in five of the cases. Ten of the cases were marked as serious and seriousness was not highlighted on the rest of cases; even though the reported reaction terms are potentially serious by definition. Adverse drug reactions are described as serious those that resulted in death or life-threatening, hospitalization/prolonged existing hospitalization, permanent/persistent disability, congenital anomalies, or required intervention to prevent permanent injury [10].

\section{Case report from Eritrea}

A 33 years old female patient underwent a fertility treatment with Clomifene Citrate $50 \mathrm{mg}$ on $28^{\text {th }}$ of October 2015. She took one cycle of treatment (for five days) two months before but stopped in the second month on her own for unknown reason. She was a one eyed woman, lost her left eye before 22 years with accident of a thorn substance when she was ten-year old. While she was on her second cycle, she experienced sudden blurred vision after two-days intake of Clomifene Citrate $50 \mathrm{mg}$ and subsequently developed to complete loss of vision in few days. She reported the problem to a community Pharmacist and advised her to visit an Ophthalmologist. On $9^{\text {th }}$ of November 2015, she visited a national referral Ophthalmic Hospital and her vision problem was diagnosed as retinal detachment. The ophthalmologist referred her to abroad for immediate management but with financial constraints she could not make it. Following this investigation, the case was reported to the Eritrean Pharmacovigilance Centre in June 2016 as 'blindness associated with Clomifene citrate'. To follow-up the case, staff of the Eritrean Pharmacovigilance Centre brought the woman again to the national referral Ophthalmic Hospital IN August

Table 1. Summary of ICSRs associated with Clomifene Citrate retrieved from the WHO global database, VigiBase ${ }^{\mathrm{TM}}$.

\begin{tabular}{|c|c|c|c|c|c|c|c|c|}
\hline & Reaction Term & Cases retrieved & $\begin{array}{c}\text { Cases with single drug } \\
\text { suspect }\end{array}$ & $\mathrm{IC}_{025}$ & IC & $\begin{array}{l}\text { No. of countries } \\
\text { reported }\end{array}$ & $\begin{array}{l}\text { Cases with positive } \\
\text { dechallenge }\end{array}$ & $\begin{array}{l}\text { Cases with positive } \\
\text { rechallenge }\end{array}$ \\
\hline 1. & Visual disorder & 353 & 345 & 3.12 & 3.28 & 21 & 79 & 20 \\
\hline 2. & Blindness & 11 & 11 & 1.06 & 2.03 & 3 & 2 & 0 \\
\hline 3. & Retinal disorder & 11 & 11 & 0.27 & 1.25 & 4 & 0 & 0 \\
\hline 4. & Retinal detachment & 02 & 2 & -3.64 & 0.16 & 2 & 0 & 0 \\
\hline
\end{tabular}

Table 2. Characteristics of patients and reactions encountered following the use of Clomifene Citrate.

\begin{tabular}{|c|c|c|c|c|c|}
\hline $\begin{array}{l}\text { Case } \\
\#\end{array}$ & Age/sex & $\begin{array}{l}\text { Other suspected (S) or } \\
\text { concomitant }(C) \text { medicines }\end{array}$ & Reaction (WHO-ART preferred term) & $\begin{array}{l}\text { Time to reaction } \\
\text { onset (days) }\end{array}$ & Outcome \\
\hline 1. & $29 / \mathrm{F}$ & None & Blindness & 90 & Recovered with sequelae \\
\hline 2. & $42 / \mathrm{F}$ & None & $\begin{array}{c}\text { Retinal disorder, Visual impairment, Photopsia, Vitreous } \\
\text { floaters }\end{array}$ & N/A & $\mathrm{N} / \mathrm{A}$ \\
\hline 3. & $-/ F$ & None & $\begin{array}{l}\text { Retinal disorder, eye inflamed, headache, Optic neuritis, } \\
\text { Papilloedema, }\end{array}$ & 02 & Not yet recovered \\
\hline 4. & $-/ \mathrm{M}$ & None & Retinal damage & N/A & N/A \\
\hline 5. & $31 / \mathrm{F}$ & Bromocriptine, Parlodel(C) & Retinal detachment, Vision abnormal & 116 & N/A \\
\hline 6. & $34 / \mathrm{F}$ & None & Retinal disorder, Vision abnormal & 61 & Unknown \\
\hline 7. & $33 / \mathrm{F}$ & None & Retinal disorder & $\mathrm{N} / \mathrm{A}$ & N/A \\
\hline 8. & $-/ F$ & None & Retinal disorder & 02 & Unknown \\
\hline 9. & $31 / \mathrm{M}$ & Ranitidine (C) & Retinal damage & N/A & Unknown \\
\hline 10. & $33 / \mathrm{F}$ & None & Retinal vascular disorder NOS & $\mathrm{N} / \mathrm{A}$ & Not recovered \\
\hline 11. & $-/ F$ & Drug name/s under assessment for WHO-DD (C) & Blindness, Vision blurred, Optic neuritis & 211 & N/A \\
\hline 12. & $-/ F$ & None & Blindness, Retinitis & 02 & Unknown \\
\hline 13. & $31 / \mathrm{F}$ & None & Blindness unilateral & N/A & Unknown \\
\hline 14. & $33 / \mathrm{F}$ & None & Blindness, Klinefelter's syndrome, Deafness & N/A & Unknown \\
\hline 15. & $-/-$ & None & Blindness, Blindness night, Photophobia, & 02 & N/A \\
\hline 16. & $-/ F$ & None & Blindness & N/A & N/A \\
\hline 17. & $-/ F$ & None & Blindness & N/A & Unknown \\
\hline 18. & $-/ \mathrm{M}$ & None & Retinopathy & N/A & Unknown \\
\hline 19. & $-/-$ & None & Retinal disorder, Vision abnormal & N/A & Unknown \\
\hline 20. & $-/-$ & None & Retinopathy & N/A & Unknown \\
\hline 21. & $33 / \mathrm{F}$ & None & Retinal Detachment & 02 & Worsen \\
\hline
\end{tabular}

N/A: Not available 
2016. She was again diagnosed to have posterior vitreous detachment with chronic rehgmatogenous retinal detachment in the right eye. The left eye was diagnosed to be a phthisis bulbi following a trauma that happened 22 years ago with a thorn substance. Detailed various ophthalmic examinations were made with two ophthalmologists and was diagnosed as a case of irreversible blindness in the right eye secondary to Clomifene Citrate and virtually became blind due to pre-existing blindness in the left eye. The case had no similar medical history or any visual problems before on her right eye. Besides, she had no history of recent head trauma/injury and other medicines or herbal intake prior to that incident.

\section{Discussion}

Assessment on the ICSRs retrieved from the WHO global database supports a causal association between Clomifene Citrate and blindness as well as retinal disorder. Vision problems have been associated with Clomifene citrate since long time. In VigiBase, 353 cases of Visual disorder were retrieved, of which 79 cases recovered following withdrawal of Clomifene citrate. Of the subsequently rechallenged cases, reaction recurred in 20 of the consumers and Clomifene citrate was the only suspected drug in most of the cases (97.7\%) with a positive IC value (Table 1). This also supports the previously established causal association between Clomifene citrate and visual disorder.

In this study, a case reported from Eritrea, developed posterior vitreous detachment and subsequently diagnosed as chronic rhegmatogenous retinal detachment. The retinal detachment was probably associated with the use of Clomifene citrate as no possible alternative cause was identified. In all the cases retrieved from VigiBase, Clomifene citrate was reported as the sole suspected drug and in all but three cases, no concomitant drugs were reported. There were two cases of blindness in which reaction abated following withdrawal of Clomifene citrate. Ten of the cases were marked as serious and seriousness was not highlighted on the rest of cases.

The plausible temporal relationship with consistent time to onset in some of the cases, the positive IC Value, the unavailability of other alternative explanations of the adverse effect in the case from Eritrea, the positive dechallenge in two other cases, the specificity of the cases and their wide geographical distribution are evidences that support a causal association. This is inconsistent with the findings by Lyne Racette, et al. [11] that concluded the effect of Clomifene citrate on vision was minimal, and the visual disturbances were reversible in all patients.

A computerized PubMed search made by Viola MI et al [5] found only four articles that describe visual problems with Clomifene citrate in fertility patients and were published as case reports. They also found two systematic reviews on the adverse effects of Clomifene and found no visual changes. To the best of our knowledge, there are no published case reports or studies that previously associate Clomifene citrate with irreversible blindness and retinal disorder or retinal detachment. Hence, it should be made clear to the patient that, in some instances, visual disturbances may be possibly irreversible, even at small doses. Besides, patients taking Clomifene citrate should be advised to stop their treatment immediately when they encounter visual problems and should visit an ophthalmologist for complete examinations.

This case assessment supports a causal association between Clomifene citrate and blindness. A case of irreversible blindness due to intake of Clomifene citrate highlights the fact that, ladies undertaking Clomifene citrate should be monitored carefully. A detailed Ophthalmic examination before the start of Clomifene citrate and regular Ophthalmic examinations after starting the drug should be considered in all subjects taking Clomifene citrate. Besides, further study is required to to further substantiate this safety signal.

\section{Authors' contributions}

The case was investigated by KF and BP. All of the authors played a key role on the analysis and interpretation of the cases. MR, BP and MZ wrote the article and edited by the rest of the authors.

\section{Author details}

Mulugeta Russom, Pharmacist, Head, Eritrean Pharmacovigilance Centre, Asmara, Eritrea

Bastola Pradeep, Retina Specialist, Consultant Ophthalmologist, Brhan Eye National Referral Hospital, Asmara, Eritrea

Mehari Zeregabr, Pharmacist, Pharmacovigilance officer, Asmara, Eritrea

Kahasay Fisahatzion, Ophthalmologist, Medical Director, Brhan Eye National Referral Hospital, Asmara, Eritrea

Natnael Araia, Pharmacist, Mendefera Zonal Referral Hospital, Mendefera, Eritrea

\section{Acknowledgements}

The authors would like to acknowledge the all the reporters for their vigilance and Berhan Eye national referral hospital for their immense support during the case investigation.

\section{Competing interests}

The authors Mulugeta Russom, Bastola Pradeep, Mehari Zeregabr, Kahasay Fisahatzion and Natnael Araia declare that they have no competing interests and no source of funding was used to carry out the study.

\section{References}

1. Adashi EY (1984) Clomiphene citrate: mechanism(s) and site(s) of action--a hypothesis revisited. Fertil Steril 42: 331-344. [Crossref]

2. Sanofi-aventis Product Information (2012) Clomiphene citrate tablets USP. Sanofiaventis U.S. LLC. Rev

3. Stewart J, Thornton P, Wilson K (2009) Clomid. Food and Drug Administration.

4. Rock T, Dinar Y, Romem M (1989) Retinal periphlebitis after hormonal treatment. Ann Ophthalmol 21: 75-76. [Crossref]

5. Viola MI, Meyer D, Kruger T (2011) Association between Clomiphene Citrate and Visual Disturbances with Special Emphasis on Central Retinal Vein Occlusion: A Review. GynecolObstet Invest 71: 73-76. [Crossref]

6. Lawton AW (1994) Optic neuropathy associated with clomiphene citrate therapy: case report. Fertil Steril 61: 390-391. [Crossref]

7. Purvin VA (1995) Visual disturbance secondary to clomiphene citrate. Arch Ophthalmol 113: 482-484. [Crossref]

8. Wockhardt (2016) UK Ltd. Clomifene 50mg Tablet. Summary product characteristics.

9. Naranjo CA, Busto U, Sellers EM, Sandor P, Ruiz I, et al. (1981) A method for estimating the probability of adverse drug reactions. Clin Pharmacol Ther 30: 239245. [Crossref]

10. CIOMS (2001) Current Challenges in Pharmacovigilance: Pragmatic Approaches. Report of CIOMS Working Group V. Geneva: Council for International Organizations of Medical Sciences. 
11. Lyne Racette, Peter R, Paul Claman, Casson, David H Zackon, et al. (2010) An investigation of the visual disturbances experienced by patients on clomiphene citrate. FertilSteril 93: 1169-1117. [Crossref]

Copyright: (C2017 Russom M. This is an open-access article distributed under the terms of the Creative Commons Attribution License, which permits unrestricted use, distribution, and reproduction in any medium, provided the original author and source are credited. 